\title{
FIELD OBSERVATIONS OF BYBLIS IN AUSTRALIA
}

THILO KRUEGER •Wiesbaden • Germany • thilozuiop@gmail.com

Over the course of several field trips undertaken since 2014, I had the opportunity to encounter all currently described species of the genus Byblis (rainbow plants) in their natural habitats in northern and south-west Australia.

The eight species can be divided into two well-separated groups: Both species from south-west Western Australia (B. gigantea and B. lamellata) are perennial subshrubs and emerge from their fleshy roots (or from their above-ground stems) after the dry season or after a bushfire.

The second group is comprised by the six species from tropical northern Australia which are annual herbs and usually die off shortly after the wet season. If, however, the habitat remains even just barely moist, many species can grow and flourish well into the dry season which typically lacks any kind of precipitation. The next generation emerges from seeds after the start of the following wet season.

There is some controversy regarding the taxonomic status of several species and some researchers believe there may only be three or four morphologically clearly separated species in the genus Byblis (A. Cross, pers. comm.). In the following, I report on my personal observations and difficulties with distinguishing the species during my extensive travels through Australia.

\section{Byblis aquatica (Fig. 1)}

During my field trip to northern Australia in July 2014, I soon noticed that most locations where I knew Byblis should occur were already completely dried up. The dry season in this area usually lasts from May to October so July was right in the middle of it. However, after some searching, I came across a very sandy and slightly damp depression which can be flooded to a depth of around $50 \mathrm{~cm}$ during much of the wet season. This is a typical habitat of Byblis aquatica and I soon noticed some of the maroon-colored plants growing only about 5-10 cm in height with a $20-30 \mathrm{~cm}$ long, creeping stem.

A very characteristic feature of B. aquatica is the morphology of the stamens. It is one of only two Byblis species which produces anthers significantly shorter than their corresponding filaments (see Fig. 2). As in most other Byblis species, kleptoparasitic bugs of the genus Setocoris are very common on these plants. It is always amazing to observe how these little insects move along the sticky leaves with ease and feed on the captured prey!

Byblis aquatica is relatively common in the Darwin region of the Northern Territory and further east to Kakadu National Park with an additional distribution area known along the northern parts of Cape York peninsula, Queensland.

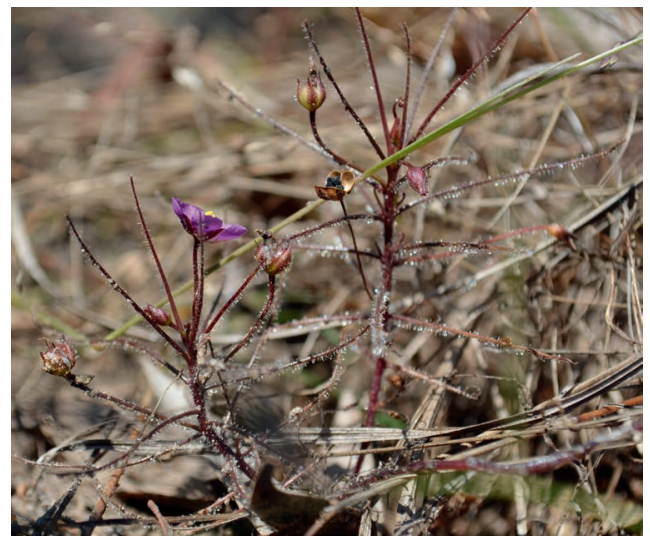

Figure 1: Byblis aquatica growing in a slightly moist habitat near Darwin during the dry season. 

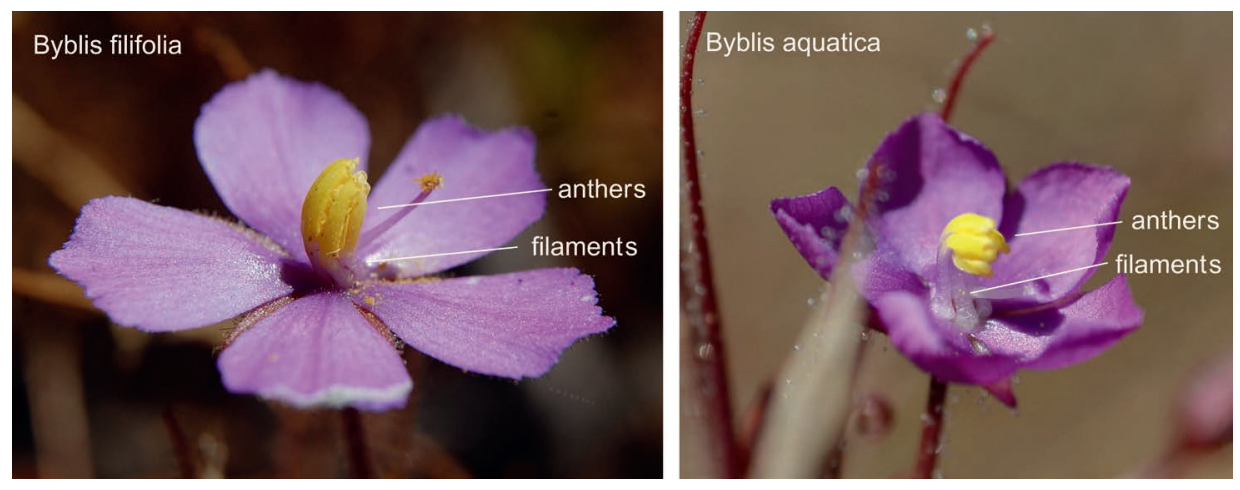

Figure 2: Comparison of the stamens of Byblis filifolia and B. aquatica.

\section{Byblis liniflora (Fig. 3)}

This is the only other species of the genus with very short anthers. During a dry-season visit to Litchfield National Park (which is ca. $80 \mathrm{~km}$ south of Darwin), I found this species growing in small crevices along the sandstone riverbed of a beautiful cascade. At most locations in the Northern Territory and the Kimberley region of Western Australia, B. liniflora seems to be a relatively small and inconspicuous plant typically occurring in very scattered populations of only a few individuals. However, at this cascade in Litchfield National Park, there were hundreds of spectacular and quite large plants growing on the bare sandstone rock. Some individuals measured more than $20 \mathrm{~cm}$ in diameter. I spent almost a full day exploring this location and discovered that there are no less than 15 additional carnivorous plant species growing within 50 meters of these $B$. liniflora - which means this is one of the most diverse sites I have ever visited in all my travels through Australia.

In March 2016 (i.e. during the wet season), I returned to the exact same cascade and instead of B. liniflora, the only thing I found was a raging river completely inundating the rock crevices where the plants grow during the dry season! It seems likely to me that, at least at this location, B. liniflora not only produces seed to survive the dry season, but to survive the raging floods of the wet season as well. The seeds seem to accumulate in the rock crevices and germinate as soon as the water level sufficiently recedes.

Byblis liniflora is closely related to $B$. aquatica and distinguishing these two can be challenging at times. The former species usually produces flower stalks which are significantly longer than in the latter, but that feature may not always be reliable. Furthermore, $B$. aquatica typically is a maroon colored plant while $B$. liniflora always produces a greenish

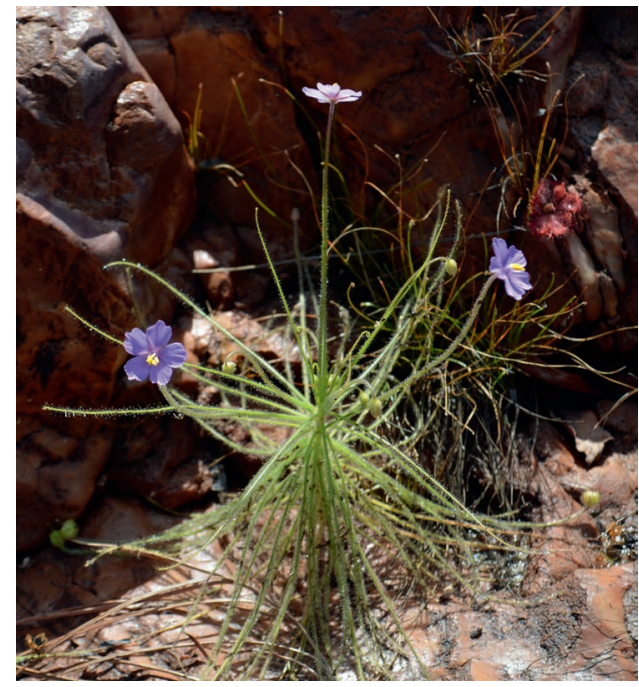

Figure 3: Byblis liniflora growing in Litchfield National Park. 
color. Another possible way to distinguish them may be the length of the tentacles in relation to the leaf width. While the tentacles of B. aquatica are usually shorter than (or only slightly longer than) the width of the leaf, B. liniflora commonly produces tentacles more than two times as long as the leaf width. These features seem to be relatively stable when both species are cultivated under similar conditions (G. Allan, pers. comm.). Interestingly, I have never seen the two species co-occurring at the same location.

This is the Byblis species with the largest distribution area, ranging from the Kimberley region of Western Australia and the Top End of the Northern Territory to large parts of the Cape York peninsula and even Papua New Guinea. Byblis liniflora is the only species of the genus currently known to occur outside of Australia.

\section{Byblis filifolia (Fig. 4)}

Around $400 \mathrm{~km}$ to the south of Litchfield National Park lies the small town of Kununurra on the eastern edge of Western Australia's Kimberley region. In this area, the by far most common species is B. filifolia which grows in a wide range of seasonally wet habitats.

In contrast to B. aquatica and B. liniflora, the anthers of $B$. filifolia are longer than (or at least the same length as) their corresponding filaments (see Fig. 2). This species seems to be highly variable and some of the most interesting forms I encountered produce almost completely white flowers with the backsides beautifully striped in red and yellow.

Throughout most parts of the Kimberley, B. filifolia seems to be a very common species. Some additional populations are known in the Top End region of the Northern Territory.

\section{Byblis rorida}

This species has been the most elusive Byblis during my travels. Despite multiple attempts during both the dry and wet seasons, I was only able to find a single plant which fully matches Allen Lowrie's (2014) descrip-

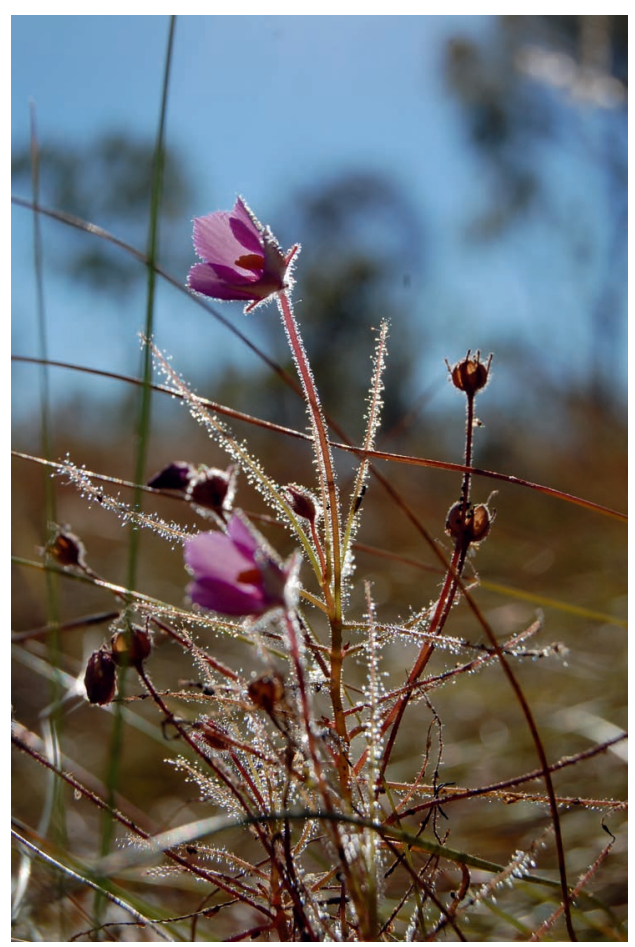

Figure 4: Glistening Byblis filifolia near Kununurra, Western Australia. tion of $B$. rorida.

Like in B. filifolia, the anthers of B. rorida are longer than or at least the same length as the filaments. However, it may be distinguished from B. filifolia by its sessile (stalkless) glands which cover the developing leaves and flower scapes. Another feature which can help with identification are the very long tentacles produced on the sepals. However, I often observed them in other species as well and the sessile glands also do not seem to be a reliable feature to distinguish $B$. rorida from its relatives. Therefore, it may be possible that this species just represents a particular form of the highly variable $B$. filifolia (A. Cross, pers. comm.). 
Byblis rorida is endemic to the Kimberley region of Western Australia where it has mostly been found in the western parts.

\section{Byblis guehoi (Fig. 5)}

The approximately 200-km-long Dampier peninsula is located at the far western end of the Kimberley. During August 2014, I encountered a lot of Byblis plants growing throughout the peninsula in a variety of different habitats which included completely dry and recently burned Eucalyptus savannah, slightly damp wet-season flooded watersheds, and even permanently wet swamps. At most sites, the plants were growing together with Drosera broomensis, a member of the $D$. petiolaris complex.

All Byblis flowers seen had anthers longer than the filaments and since B. filifolia has never been recorded from this peninsula, I believed these plants to be either $B$. rorida or B. guehoi. The latter species is best known for its multi-branched growth habit, sometimes producing ten or more shoots. Howev-

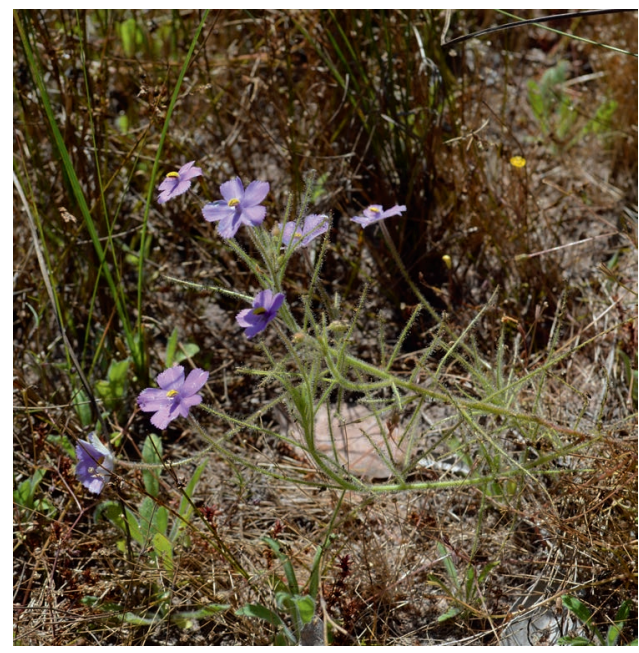

Figure 5: Branched Byblis guehoi growing at a permanently wet swamp near the eastern coast of the Dampier peninsula. er, I soon realized that the species occurring across the peninsula are not easy to identify - even at the type location of B. guehoi! Most plants I found were not at all or only slightly branched and often produced very long tentacles on their sepals. Although these two characters would normally suggest $B$. rorida, sessile glands on the young leaves and flower stalks were constantly lacking. For this reason, it is likely that the plants I found there are exclusively B. guehoi (at least if considered to be a valid species, see below). This species is currently thought to be endemic to the Dampier peninsula.

Byblis guehoi was described based on particularly strongly branched specimens (A. Fleischmann, pers. comm.) and usually seems to be much less branched at most locations. At an extremely remote and permanently wet swamp located in the eastern part of the peninsula, I could finally find some highly branched specimens of $B$. guehoi which look relatively close to the type.

However, I could often observe multi-branching specimens in B. filifolia as well and, although currently thought to be geographically separated, these two species indeed seem to be very difficult or even impossible to distinguish.

\section{Byblis pilbarana (Fig. 6)}

The habitat of B. pilbarana - the most recently described species of the genus - is located more than $600 \mathrm{~km}$ to the southwest of the Dampier peninsula. Also called the Pilbara, this region differs markedly from the savannah landscape of northern Australia. With an average annual rainfall of only around $300 \mathrm{~mm}$ falling in one of the hottest places on earth (temperatures very close to $50^{\circ} \mathrm{C}$ are not uncommon during the summer months!), the Pilbara is characterised by a semi-arid desert 
climate where carnivorous plants can only survive in very special niches.

One such a niche is "Red Rock", an approximately $300 \mathrm{~m}$ wide and $40 \mathrm{~m}$ tall inselberg 60 $\mathrm{km}$ to the south of the mining town of Port Hedland. Due to its reddish color, "Red Rock" reminds me a little bit of the world-famous U1uru (Ayers Rock). Strangely, one of the worst aviation disasters of Australia occurred very close to this location on New Year's Eve 1968, when a flight with 26 people on board crashed. A memorial and even some pieces of wreckage are located adjacent to the inselberg.

During my visit at the end of August 2014, I was only able to find ca. 20-30 individual specimens of $B$. pilbarana growing exclusively at the north-eastern edge of "Red Rock". Interestingly, the only other carnivorous plant I could find in the whole Pilbara region (Drosera finlaysoniana), occurred only on the south-western, opposite end of the same rock where just six plants grew in a single crevice. These two spots are exactly the areas of the inselberg where the most water accumulates during rare rain events. Therefore, they remain

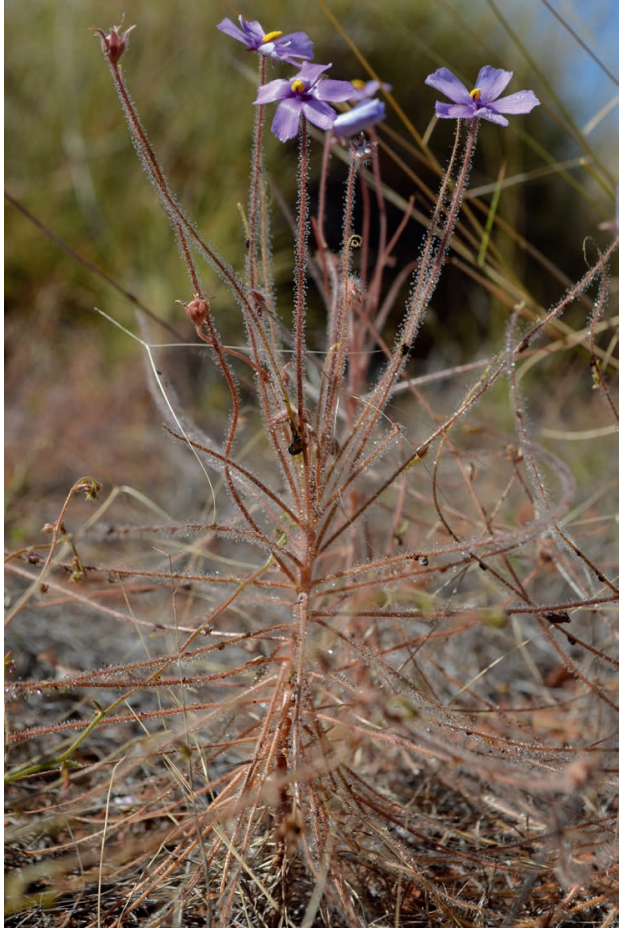

Figure 6: Byblis pilbarana growing at Red Rock. moist for much longer than the surrounding areas. Snakes seem to prefer these slightly more humid places as well, because I encountered two of the most poisonous Australian snakes there: A brown snake (Pseudonaja sp.) in tall grasses and a young desert death adder (Acanthophis pyrrhus) on the bare rock.

Byblis pilbarana is a very impressive species with a relatively short and thick stem. It has anthers which are longer than the filaments and overall looks very similar to B. filifolia and B. rorida. It differs from the latter species by its unusual seeds and the absence of sessile glands on the developing leaves and flower stalks. However, the morphological differences between B. pilbarana and $B$. filifolia/B. guehoi/B. rorida seem to be quite minor and it is possible that all four may represent one highly variable species (A. Cross, pers. comm.).

This species is currently known from just a few locations around Port Hedland and it is the only carnivorous plant endemic to the semi-arid Pilbara region of Western Australia.

\section{Byblis lamellata (Fig. 7)}

Even from the Pilbara, the distribution area of the two perennial Byblis species from south-west Western Australia is located more than 1,000 km to the south. During September 2014, I had the opportunity to thoroughly search the area around the small town of Eneabba which only has around 250 inhabitants. Eneabba is situated in the Mediterranean climate of the south-west which means September is actually part of the wet season! Accordingly, the predominant heathland vegetation of the area was full of beautiful flowers during that time. I was able to find many different Stylidium 


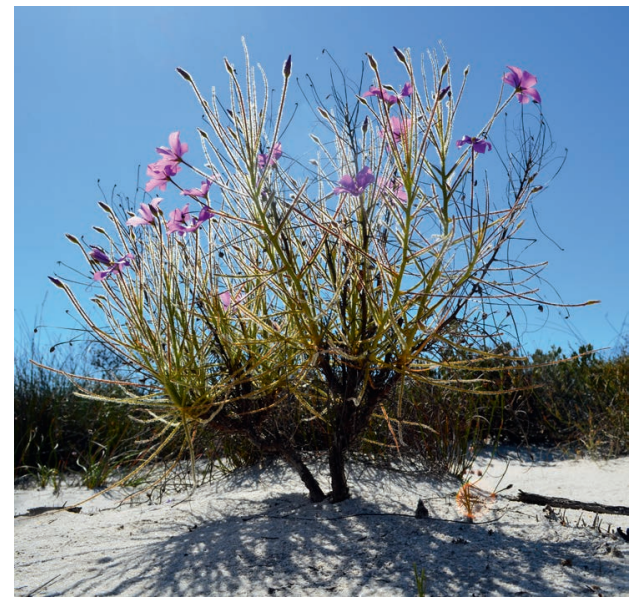

Figure 7: An exceptionally large specimen of Byblis lamellata growing close to Eneabba.

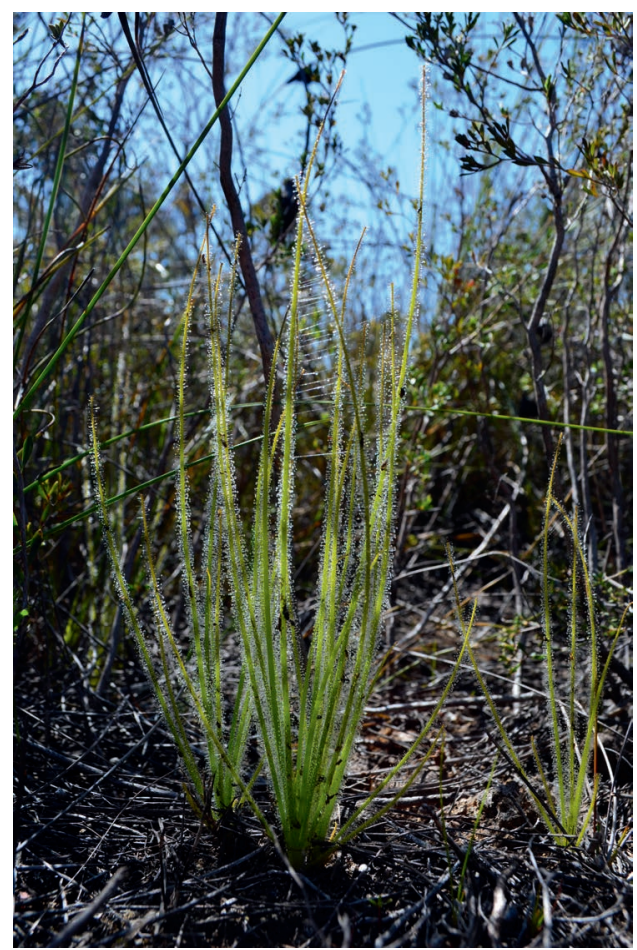

Figure 8: Byblis gigantea growing in a swamp habitat near Perth. species, the fascinating orchids of the genus Caladenia and of course lots of different tuberous and pygmy sundews growing between the flowering bushes. However, B. lamellata turned out to be an exceptionally difficult species to find!

Despite being described as "locally common" at several locations, it was only after a dedicated four-day long search when I first came across a single $B$. lamellata. But that plant was a beast! With a diameter of ca. 60 $\mathrm{cm}$, the plant was about three to four times larger than anything I've seen in the tropical north and can be described as a true shrub due to its thick woody stem which develops more than 15 individual shoots. It was growing together with the pygmy sundew Drosera eneabba and the tuberous sundew D. porrecta.

On the same plant, I could again observe kleptoparasitic Setocoris bugs. But unlike the bugs from northern Australia, they were wingless and resembled ants due to their dark color. These bugs certainly belong to the species Setocoris bybliphilus.

Byblis lamellata seems to be a rare species only infrequently occurring at a few known locations around Eneabba and Warradarge, ca. $230 \mathrm{~km}$ north of Perth. Inadequate fire management and sand mining activities may be possible reasons for the apparent decline in population numbers (A. Cross, pers. comm.).

\section{Byblis gigantea (Fig. 8)}

This species has an even more southernly distribution area. It occurs in a narrow area around the large city of Perth where it is only known from four relatively small populations. Despite extensive searches, I was unfortunately not able to locate any additional sites. Furthermore, I could only find four individual plants of $B$. gigantea at the two known locations I visited. This species is certainly the rarest and most threatened of all Byblis!

Its habitat differs significantly from the dry, sandy habitat of $B$. lamellata since it only 
occurs in seasonally wet swamps where moisture is present for a large part of the year. Therefore, other carnivorous plants which are favoring damp habitats (i.e. Drosera occidentalis, D. myriantha, D. nitidula and Utricularia petertaylorii) can be found growing together with $B$. gigantea.

Despite being geographically well separated and occurring in very different habitats, $B$. gigantea and $B$. lamellata are very closely related and distinguishing them based on morphological features is very difficult or even impossible. While $B$. gigantea typically only resprouts from its underground rootstock after the dry season or after a fire, B. lamellata often produces an aerial stem from which it can resprout. However, the two species produce quite different seeds, and this may be the most reliable morphological feature to distinguish them.

\section{Reference}

Lowrie, A. 2014. Carnivorous Plants of Australia: Magnum Opus, volumes 1, 2, 3. Redfern Natural History Productions Ltd., Poole.

Disclaimer: This article is a translated and updated version of an article originally published in issue 81 of Das Taublatt (2015) [with permission].

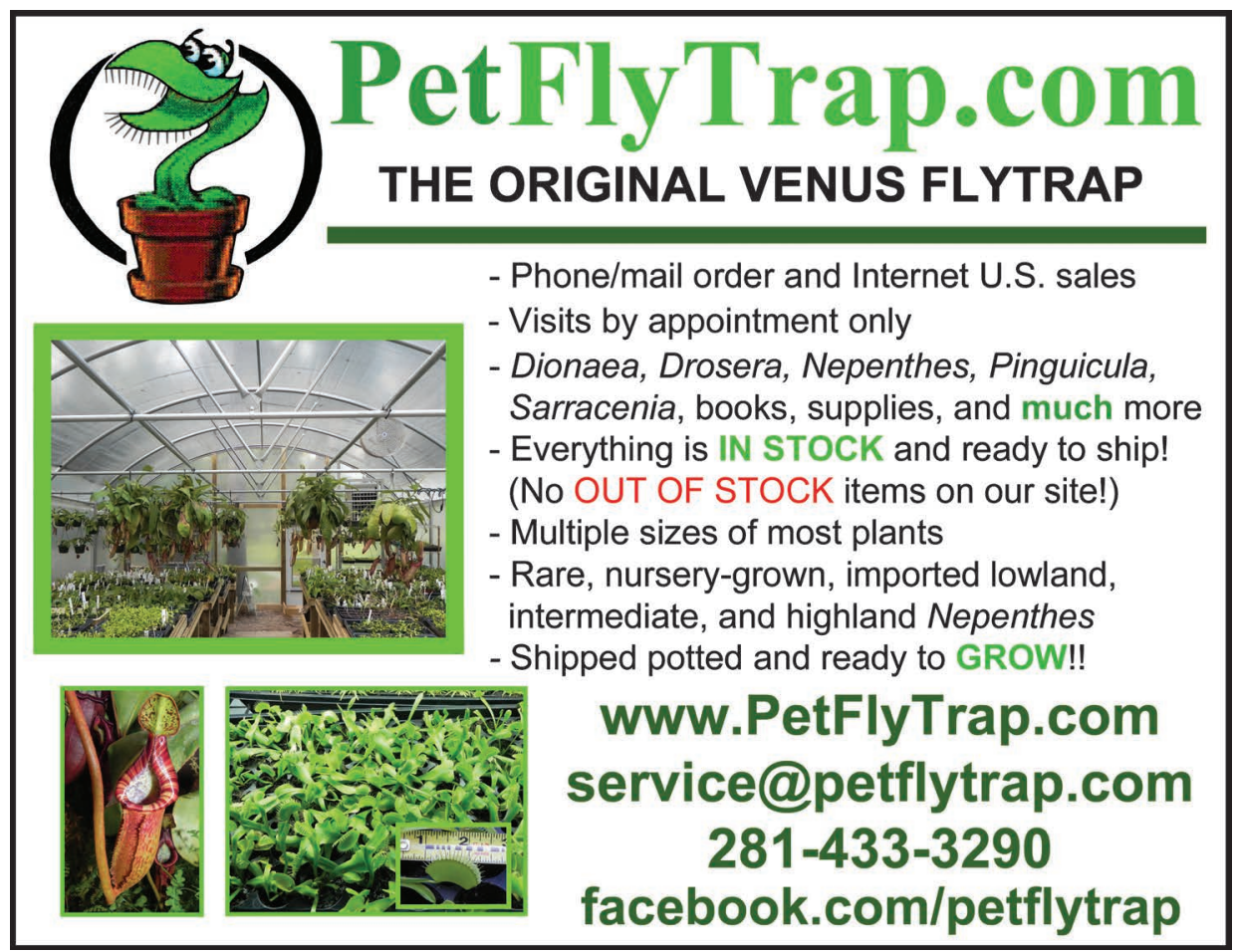

